\title{
Mutational analysis of 65 Wilson disease patients in Hong Kong Chinese: Identification of 17 novel mutations and its genetic heterogeneity
}

\author{
Chloe Miu Mak $\cdot$ Ching-Wan Lam · Sidney Tam $\cdot$ Ching-Lung Lai $\cdot$ Lik-Yuen Chan $\cdot$ Sheung-Tat Fan \\ Yu-Lung Lau · Sik-To Lai · Patrick Yuen · Joannie Hui · Chun-Cheung Fu · Ka-Sing Wong • \\ Wing-Lai Mak · Kong Tze · Sui-Fan Tong · Abby Lau · Nancy Leung $\cdot$ Aric Hui · Ka-Ming Cheung \\ Chun-Hung Ko · Yiu-Ki Chan · Oliver Ma · Tai-Nin Chau · Alexander Chiu · Yan-Wo Chan
}

Published online: 7 March 2008

(c) The Japan Society of Human Genetics and Springer 2008

\section{Erratum to: J Hum Genet (2008) 53:55-63}

DOI 10.1007/s10038-007-0218-2

The correct name of the eighth author should be given as

Sik-To Lai, not Jak-Yiu Lai.

The online version of the original article can be found under doi:10.1007/s10038-007-0218-2.

\section{M. Mak · C.-W. Lam (ه) - S.-F. Tong · A. Lau} Department of Chemical Pathology, The Chinese University of Hong Kong, Prince of Wales Hospital, Shatin,

Hong Kong, China

e-mail: ching-wanlam@cuhk.edu.hk

C. M. Mak $\cdot$ S. Tam $\cdot$ O. Ma

Division of Clinical Biochemistry,

Queen Mary Hospital, Hong Kong, China

\section{C.-L. Lai}

Department of Medicine, The University of Hong Kong,

Queen Mary Hospital, Hong Kong, China

\section{L.-Y. Chan · K.-S. Wong}

Department of Medicine and Therapeutics,

The Chinese University of Hong Kong, Prince of Wales

Hospital, Hong Kong, China

\section{S.-T. Fan}

Department of Surgery, The University of Hong Kong,

Queen Mary Hospital, Hong Kong, China

\section{Y.-L. Lau}

Department of Pediatrics and Adolescent Medicine,

The University of Hong Kong, Queen Mary Hospital,

Hong Kong, China

\section{S.-T. Lai}

Department of Medicine and Geriatrics,

Princess Margaret Hospital, Hong Kong, China
P. Yuen · J. Hui · C.-C. Fu

Department of Pediatrics, The Chinese University of Hong Kong, Prince of Wales Hospital, Hong Kong, China

\section{W.-L. Mak}

Department of Pathology, Tuen Mun Hospital,

Hong Kong, China

K. Tze

Department of Pediatrics, Tuen Mun Hospital,

Hong Kong, China

N. Leung $\cdot$ A. Hui

Department of Medicine, Alice Ho Miu Ling

Nethersole Hospital, Hong Kong, China

K.-M. Cheung · C.-H. Ko

Department of Pediatrics and Adolescent Medicine,

Caritas Medical Center, Hong Kong, China

Y.-K. Chan

Department of Medicine and Geriatrics,

Caritas Medical Centre, Sham Shui Po, Hong Kong, China

T.-N. Chau

Department of Medicine and Geriatrics,

United Christian Hospital, Hong Kong, China

A. Chiu

Department of Adult Intensive Care Unit,

Queen Mary Hospital, Hong Kong, China

Y.-W. Chan

Department of Pathology, Princess Margaret Hospital,

Hong Kong, China 